\title{
Non-disclosing youth: a cross sectional study to understand why young people do not disclose suicidal thoughts to their mental health professional.
}

\author{
Lauren McGillivray ( $\nabla$ l.mcgillivray@unsw.edu.au ) \\ Black Dog Institute \\ Demee Rheinberger \\ Black Dog Institute \\ Jessica Wang \\ Black Dog Institute \\ Alexander Burnett \\ Black Dog Institute \\ Michelle Torok \\ Black Dog Institute
}

\section{Research Article}

Keywords: suicide prevention, youth suicide, disclosure, mental health professionals

Posted Date: September 28th, 2021

DOI: https://doi.org/10.21203/rs.3.rs-922333/v1

License: (c) (1) This work is licensed under a Creative Commons Attribution 4.0 International License.

Read Full License

Version of Record: A version of this preprint was published at BMC Psychiatry on January 4th, 2022. See the published version at https://doi.org/10.1186/s12888-021-03636-x. 


\section{Abstract \\ Background}

Prevalence of suicidal ideation increases rapidly in adolescence, and many choose not to seek help and disclose their ideation. Young people who do disclose suicidal ideation, prefer to do so with peers and family compared to mental health professionals, who are best placed to provide evidence-based treatment. This study aimed to identify key factors associated with young people's decision to, or not to disclose suicidal thoughts to their mental health practitioner.

\section{Methods}

A community-based sample of young Australians (16-25 years), who had experienced suicidal ideation and engaged with a mental health professional, completed an online questionnaire $(N=513)$ which assessed demographic characteristics, severity of depression, anxiety, psychological distress, and suicidal ideation, lifetime suicide attempts, exposure to suicide loss, personal suicide stigma, prioritisation of mental health issues, and therapeutic alliance. Logistic regression analyses were used to identify factors associated with disclosure.

\section{Results}

Though the full sample had engaged in therapy, 39\% had never disclosed suicidal ideation to their clinician. Those who had disclosed were more likely to report greater prioritisation of suicidal ideation $(\mathrm{OR}=4.07,95 \% \mathrm{Cl}=2.34-7.09)$, therapeutic alliance $(\mathrm{OR}=1.04,95 \% \mathrm{Cl}=1.02-1.06)$, and personal suicide stigma $(O R=1.04,95 \% \mathrm{Cl}=1.01-1.06)$. The most common reason for not disclosing was concern that it would not remain confidential.

\section{Conclusion}

These findings provide new insights into why young people may not seek help for suicidal ideation, despite being engaged with a mental health professional, and establish evidence to inform practice decisions and the development of prevention strategies to support young people for suicide.

\section{Background}

Youth suicide prevention is a global priority as intentional self-harm is one of the leading causes of death amongst youth (World Health Organization, 2019). Suicidal ideation is an important target for youth suicide prevention efforts, with evidence that ideation increases the risk of a future suicide attempt in around one-third of young people (Nock et al., 2013). Furthermore, suicidal ideation is one of the most common behaviours on the spectrum of suicidality, affecting around 15 to $29 \%$ of adolescents and 
young adults (Donath et al., 2019; Nock et al., 2008). Given increasing evidence demonstrating a pathway from ideation to suicide attempt (Miranda et al., 2014; Voss et al., 2019), the high prevalence of youth suicidal ideation is a matter of concern. While the best approach to treating suicidal ideation is through traditional therapeutic interventions (e.g., dialectical behavioural therapy and cognitive-behavioural therapy) delivered in clinical settings (DeCou et al., 2019; Leavey \& Hawkins, 2017) a number of barriers exist preventing indicated populations from accessing such services.

Despite member states of the World Health Organization committing to the implementation of a mental health action plan in 2013 (World Health Organization, 2013), it is estimated that approximately one-third of people with past-year suicide ideation, plans, and/or attempts fail to seek and receive help (Hom et al., 2015). Of the young people who do disclose their suicidal ideation, primarily they choose to do so with parents and peer groups rather than mental health professionals (i.e., psychologists, school counsellors) (Rowe et al., 2014). This preference of disclosing to social support networks occurs despite many young people having access to mental health professionals via school or other settings (see Watanabe et al., 2012). While help-seeking through close family and friends is encouraged, members of these social networks often report they lack the confidence and skills to appropriately support the young person experiencing suicidal distress (Hooven, 2013; Walsh et al., 2013). As a result, this pathway can leave at risk young persons insufficiently supported (Frey et al., 2015; Griffiths et al., 2011).

To date, there have been no studies which have examined the number of young persons who choose not to disclose their suicidal ideation, even when they are connected to a mental health professional. Theoretically, there are a number of barriers that could feasibly prevent disclosure of suicidal thoughts and behaviours to clinicians, including perceived stigma (Rickwood et al., 2005; Sheehan et al., 2019), difficulties communicating the need for help, concerns around a lack of privacy, mistrust of an unknown person, and beliefs that professional help will not be effective (Michelmore \& Hindley, 2012; Radez et al., 2020). Given that non-disclosure may prevent vulnerable young people from receiving targeted support for suicidal ideation - which has been shown elsewhere to require approaches that differ from depression or anxiety (Meerwijk et al., 2016; Torok et al., 2020) - it is important to understand the extent to which non-disclosure is an issue and why it occurs.

Accordingly, the key aims of this study are to:

1. Establish the prevalence of non-disclosure of suicidal ideation to a mental health professional among young people aged 16 to 25 years who are currently, or recently been, in treatment.

2. Identify the key reasons why young people decide not to disclose suicidal ideation to their mental health practitioner.

This novel study is the first the authors are aware of to explore the experience of, and reasoning behind, a young person's decision to withhold disclosure of suicidal thoughts from a mental health professional. These insights could inform the development of policy and practice strategies to improve clinical care for young people with suicidal ideation. 


\section{Methods}

\section{Study design and recruitment}

An online cross-sectional survey was designed and advertised to a community-based sample of young Australians. Ethics approval for this study was obtained from the University of New South Wales Human Research Ethics Committee (HC200465).

Potential participants completed a short screening survey to determine eligibility based on the following criteria: aged 16 to 25 years, living in Australia, fluent in English, had experienced suicidal thoughts in the past 12 months, and had engaged with a mental health practitioner for any reason in the past 12 months. Participants aged 16 and 17 years could participate without parental consent provided they were deemed Gillick competent (Griffith, 2016). There were no study exclusion criteria.

The survey was published using the online survey platform Qualtrics on October 9th 2020, and data collection remained open until the recruitment objective was met $(N=513)$ (12th October 2020). During this period, the survey was promoted on social media via targeted Facebook advertisements (target parameters: ages 16-25, Australia, interests in National Suicide Prevention, Lifeline, Suicide prevention, Beyondblue, Headspace, Lifeline, R U OK Day, SANE). When a potential participant clicked on the study advertisement, they were directed to an online study portal and asked to provide individual digital consent before completing a five-item screening survey to determine eligibility. Participants who did not meet the inclusion criteria were directed to a webpage thanking them for their time and which provided relevant support contacts, such as Kids Helpline and Lifeline phone numbers and webchat addresses. Participants who met the study inclusion criteria were directed to complete a 20-minute online self-report structured questionnaire, which also included free text options for questions relating to reasons why they chose whether or not to disclose suicidal thoughts to their mental health practitioner, and what would motivate them to disclose to a mental health professional in future. Participants who completed the survey were emailed a \$10 e-gift voucher as compensation for their time.

\section{Measures}

Demographic characteristics were measured to describe the sample, including age, sex, gender identity, sexual orientation, rural/remote or metropolitan location, relationship status, and mental health status.

\section{Disclosure}

of suicidal ideation (primary outcome) was measured with the question, "Have you told your mental health professional that you have suicidal thoughts?" ('yes' or 'no'). A follow-up open ended question was asked based on the response: "What factors made you choose to tell them you have suicidal thoughts?" or "What factors made you choose not to tell them you have suicidal thoughts?". Open ended questions included multiple choice response options based on common reasons observed in the literature and free- 
text options. We also asked participants, "Can you tell us what sort of things would make you more likely to tell a mental health professional that you have suicidal thoughts?".

Suicidal ideation was measured using the Suicidal Ideation Attributes Scale (SIDAS, van Spijker et al., 2014). The SIDAS consists of 5 self-reported items rated on a 10-point scale (0 to 10). The scale provides a total score ranging from 0 to 50 , with a higher score indicating greater suicidal ideation severity. Negatively worded items are reversed scored and scores of 21 or greater indicate a high risk for suicidal behaviour (attempt). The scale has demonstrated excellent internal consistency ( $\alpha=.91$, van Spijker et al., 2014).

Depressive symptoms were measured by the Patient Health Questionnaire Depression Scale (PHQ-9, Kroenke et al., 2001). This scale consists of 9 items rated on a 4-point scale, ranging from 0 (not at all) to 3 (nearly every day). Higher scores indicate the presence of more depressive symptoms, and the maximum total score is 27 . The scale has demonstrated good internal consistency ( $a>.80$, Kroenke et al., 2016).

Anxiety symptoms were measured by the Generalised Anxiety Disorder-7 Scale (GAD-7, Spitzer et al., 2006). The GAD-7 consists of 7 self-reported items rated on a 4-point scale $(0=$ not at all to $3=$ nearly every day), with a total score ranging from 0 to 21 and higher scores indicating more severe anxiety symptoms. The scale has demonstrated good internal ( $a>.80$, Kroenke et al., 2016)

Psychological distress was measured using the Distress Questionnaire-5 (DQ5, Batterham et al., 2016), which consists of 5 self-reported items rated on a 5 -point scale $(1=$ never to $5=$ always $)$. The scale provides a total score ranging from 5 to 25 , with a higher score indicating greater psychological distress. The scale has demonstrated good internal consistency $(a=.86$, Batterham et al., 2016).

Suicide attempt (lifetime history) was assessed with the question "Have you ever attempted suicide?" ('no, never', 'yes, once', or 'yes, more than once'). For participants who answered more than once, an additional question asked them to specify the number of attempts.

Exposure to suicide loss was measured by asking, "Has anyone close to you died by suicide?" 'yes' or 'no'. This question was a modified from a recent study by Maple and Sanford (2020).

Personal suicide stigma was measured using the Personal Suicide Stigma Questionnaire (PSSQ, Rimkeviciene et al., 2019), which consists of 16 self-reported items rated on a 5 -point scale ( $1=$ never to 5 $=$ very often). The scale provides a total score ranging from 16 to 80 , with a higher score indicating suicide-related stigma experiences. The scale has demonstrated excellent internal consistency $(a=.96$, Rimkeviciene et al., 2021).

Prioritisation of mental health issues was measured with the question, "In the following list of mental health problems, we'd like you to rank the top 3 , according to how important these are to you when talking to your mental health professional.". Respondents could rank a list of ICD-10 categories of mental health 
diagnoses, including suicidal thoughts, from 1 (most important) to 3 (less important). Prioritisation of suicidal ideation specifically (ranked as top 3; 'yes' or 'no'), was used in regression analyses.

Therapeutic alliance was measured using the Revised Helping Alliance Questionnaire (HAq-II, Luborsky et al., 1996), which asks respondents to carefully consider their relationship with their most recent therapist and rate 19 items on 6-point scale according to how strongly they disagree (1) to agree (6) regarding the mutual collaboration and bond between client and therapist. The scale provides a total score ranging from 19 to 114, with a higher score indicating greater alliance with the therapist. Negatively worded items are reversed scored. The scale has demonstrated excellent internal consistency ( $\alpha \geq .90$, Barber et al., 1999).

\section{Statistical Analysis}

To detect non-disclosure of suicidal ideation in the cohort (primary outcome), a total minimum sample size of $n=471$ was needed. This estimate accounts for a youth population-level incidence of 12-month suicide ideation of $26 \%$ (Nock et al., 2008) and a $34 \%$ rate of suicidal ideation in a youth population engaged with mental health services (Bruffaerts et al., 2011), with power set at $90 \%$, alpha set at 0.01 .

Descriptive information was presented as proportions (\%) and means (with standard deviation; SD). Ttests and chi-square $(\chi 2)$ tests were conducted to establish whether the participants who did and did not disclose suicidal ideation differed significantly on demographic and clinical characteristics. Significant variables (with a more liberal cut-off of $p<.10$, see Ranganathan et al., 2017) were chosen to be entered into a subsequent binary logistic regression model to examine what factors are independently associated with disclosure of suicidal ideation to a mental health professional. In this model, disclosure (yes/no) as the dependent variable was used to estimate odds ratios (ORs) with $95 \%$ confidence intervals (Cls).

Quantitative data were analysed using SPSS version 25.0, alpha was set at $p<.05$ for interpreting significant effects. The following guidelines were used to interpret effect sizes: correlation coefficient ( $r$ ) values of .10, .30, .50, and .70, correspond to small, medium, large, and very large effect sizes, respectively (Cohen, 2013); Phi $(\phi)$ values of .10, .20, .30, and .40, correspond to small, medium, large, and very large effect sizes, respectively (Funder \& Ozer, 2019); ORs of 1.44, 2.48, and 4.27 correspond to small, medium, and large effect sizes, respectively (Cohen, 2013); raw means were calculated to estimate Cohen's $d$, with values of $.20, .50$, and .80 corresponding to small, medium, and large effect sizes, respectively.

Free-text responses were qualitatively analysed using reflexive thematic analysis via NVivo version 12 . Responses were thematically analysed, with similar responses grouped together by two authors (LM and DR) independently. Individual responses were then reviewed between the two authors and discrepancies were discussed until agreement was reached.

\section{Results}




\section{Descriptive statistics}

In total 513 participants completed the survey, with a median age of 17 years. The majority of participants reported being diagnosed with a mental disorder $(n=412,80.3 \%)$. Other demographic characteristics are displayed in Table 1.

Most participants reported having disclosed suicidal thoughts to another person ( $n=413,81.9 \%)$, however when asked if they had disclosed to a mental health professional more than one third said they had not $(n=191,39 \%)$. In ranking the importance of different mental health issues when talking to a mental health professional, 304 (59.3\%) participants prioritised suicidal ideation as being important, but depressive $(n=349,68 \%)$ and anxiety-related disorders $(n=328,63.9 \%)$ were prioritised as the top two concerns. Other clinical characteristics are displayed in Table 1.

\section{Characteristics Of Non-disclosure}

Sample characteristics by disclosure status (disclosure, non-disclosure) are reported in Table 1 alongside significance testing and effect sizes. Disclosure was significantly associated with sexual minority status, prioritisation of suicidal ideation, a history of suicide attempt, having disclosed to another person in the past, greater suicidal ideation severity, greater personal suicide stigma, and greater therapeutic alliance with their most recent therapist. 
Table 1

Sample Characteristics and Disclosure of Suicidal Ideation to a Mental Health Professional

\begin{tabular}{|c|c|c|c|c|}
\hline & $\begin{array}{l}\text { Total } \\
\text { sample }\end{array}$ & $\begin{array}{l}\text { No } \\
\text { disclosure }\end{array}$ & Disclosure & $\begin{array}{l}\text { Significance test and effect } \\
\text { size }\end{array}$ \\
\hline \multirow{2}{*}{$\begin{array}{l}\text { Gender } \\
\text { Female } \\
\text { Male }\end{array}$} & $\begin{array}{l}429 \\
(83.8 \%)\end{array}$ & $\begin{array}{l}161 \\
(84.3 \%)\end{array}$ & $\begin{array}{l}251 \\
(83.9 \%)\end{array}$ & \multirow[t]{2}{*}{$\chi^{2}(1) .01, p=.919, \phi=.005$} \\
\hline & $83(16.2 \%)$ & 30 (15.7\%) & $\begin{array}{l}48 \\
(16.1 \%)\end{array}$ & \\
\hline \multirow{2}{*}{$\begin{array}{l}\text { Sexuality } \\
\text { Heterosexual } \\
\text { Sexual minority }\end{array}$} & $\begin{array}{l}161 \\
(31.4 \%)\end{array}$ & \multirow{2}{*}{$\begin{array}{l}78(40.8 \%) \\
113 \\
(59.2 \%)\end{array}$} & $\begin{array}{l}74 \\
(24.7 \%)\end{array}$ & \multirow{2}{*}{$\begin{array}{l}\chi^{2}(1) 14.10, p<.001 *, \phi \\
=.170\end{array}$} \\
\hline & $\begin{array}{l}352 \\
(68.6 \%)\end{array}$ & & $\begin{array}{l}225 \\
(75.3 \%)\end{array}$ & \\
\hline \multirow{2}{*}{$\begin{array}{l}\text { Language at home } \\
\text { English only } \\
\text { Multilingual }\end{array}$} & $\begin{array}{l}460 \\
(89.7 \%)\end{array}$ & $\begin{array}{l}173 \\
(90.6 \%)\end{array}$ & $\begin{array}{l}267 \\
(89.3 \%)\end{array}$ & \multirow[t]{2}{*}{$\chi^{2}(1) .21, p=.648, \phi=.021$} \\
\hline & $53(10.3 \%)$ & $18(9.4 \%)$ & $\begin{array}{l}32 \\
(10.7 \%)\end{array}$ & \\
\hline \multirow{2}{*}{$\begin{array}{l}\text { Relationship status } \\
\text { Single/not dating } \\
\text { Partner/dating }\end{array}$} & $\begin{array}{l}367 \\
(71.5 \%)\end{array}$ & $\begin{array}{l}148 \\
(77.5 \%)\end{array}$ & $\begin{array}{l}202 \\
(67.6 \%)\end{array}$ & \multirow{2}{*}{$\begin{array}{l}\chi^{2}(1) 5.63, p=.018, \phi \\
=.107\end{array}$} \\
\hline & $146(28.5)$ & $43(22.5 \%)$ & $\begin{array}{l}97 \\
(32.4 \%)\end{array}$ & \\
\hline \multirow{2}{*}{$\begin{array}{l}\text { Location } \\
\text { Metropolitan } \\
\text { Rural/remote }\end{array}$} & $\begin{array}{l}401 \\
(78.5 \%)\end{array}$ & $\begin{array}{l}153 \\
(80.1 \%)\end{array}$ & $\begin{array}{l}233 \\
(78.5 \%)\end{array}$ & \multirow[t]{2}{*}{$\chi^{2}(1) .19, p=.661, \phi=.020$} \\
\hline & $\begin{array}{l}110 \\
(21.5 \%)\end{array}$ & 38 (19.9) & $\begin{array}{l}64 \\
(21.5 \%)\end{array}$ & \\
\hline $\begin{array}{l}\text { Prioritisation of suicidal } \\
\text { ideation }\end{array}$ & $\begin{array}{l}209 \\
(40.7 \%)\end{array}$ & $\begin{array}{l}112 \\
(58.6 \%)\end{array}$ & $\begin{array}{l}78 \\
(26.1 \%)\end{array}$ & $\begin{array}{l}\chi^{2}(1) 52.02, p<.001 *, \phi \\
=.326\end{array}$ \\
\hline $\begin{array}{l}\text { No } \\
\text { Yes }\end{array}$ & $\begin{array}{l}304 \\
(59.3 \%)\end{array}$ & 79 (41.4\%) & $\begin{array}{l}221 \\
(73.9 \%)\end{array}$ & \\
\hline \multirow{2}{*}{$\begin{array}{l}\text { Lifetime suicide attempt } \\
\text { No } \\
\text { Yes }\end{array}$} & $\begin{array}{l}273 \\
(53.6 \%)\end{array}$ & $\begin{array}{l}137 \\
(71.7 \%)\end{array}$ & $\begin{array}{l}123 \\
(41.1 \%)\end{array}$ & \multirow[t]{2}{*}{$\begin{array}{l}\chi^{2}(1) 43.79, p<.001 *, \phi \\
=.299\end{array}$} \\
\hline & $\begin{array}{l}236 \\
(46.4 \%)\end{array}$ & $54(28.3 \%)$ & $\begin{array}{l}176 \\
(58.9 \%)\end{array}$ & \\
\hline Exposure to suicide loss & $\begin{array}{l}416 \\
(81.9 \%)\end{array}$ & $\begin{array}{l}161 \\
(84.7 \%)\end{array}$ & $\begin{array}{l}237 \\
(79.3 \%)\end{array}$ & $\begin{array}{l}\chi^{2}(1) 2.30, p=.130, \phi \\
=.069\end{array}$ \\
\hline Yes & 92 (18.1\%) & $29(15.3 \%)$ & $\begin{array}{l}62 \\
(20.7 \%)\end{array}$ & \\
\hline
\end{tabular}




\begin{tabular}{|c|c|c|c|c|}
\hline & $\begin{array}{l}\text { Total } \\
\text { sample }\end{array}$ & $\begin{array}{l}\text { No } \\
\text { disclosure }\end{array}$ & Disclosure & $\begin{array}{l}\text { Significance test and effect } \\
\text { size }\end{array}$ \\
\hline Disclosed to anyone & $91(18.1 \%)$ & $80(41.9 \%)$ & $5(1.7 \%)$ & \multirow{3}{*}{$\begin{array}{l}\chi^{2}(1) 131.45, p<.001^{*}, \phi \\
=.518\end{array}$} \\
\hline No & $\begin{array}{l}413 \\
(81.9 \%)\end{array}$ & $\begin{array}{l}111 \\
(58.1 \%)\end{array}$ & $\begin{array}{l}294 \\
(98.3 \%)\end{array}$ & \\
\hline \multicolumn{4}{|l|}{ Yes } & \\
\hline Age (years M, SD) & $17.6(1.9)$ & $\begin{array}{l}17.36 \\
(1.83)\end{array}$ & $\begin{array}{l}17.71 \\
(2.05)\end{array}$ & $\begin{array}{l}t(488)=-1.91, p=0.057, d \\
=.191\end{array}$ \\
\hline Depression $^{\mathrm{a}}(\mathrm{M}, \mathrm{SD})$ & $\begin{array}{l}27.45 \\
(5.33)\end{array}$ & $26.99,5.02$ & $\begin{array}{l}27.94 \\
5.43\end{array}$ & $\begin{array}{l}\mathrm{t}(488)=-1.94, \mathrm{p}=0.053, \mathrm{~d} \\
=.189\end{array}$ \\
\hline Anxiety $^{b}(M, S D)$ & $\begin{array}{l}20.31 \\
(4.97)\end{array}$ & $20.48,4.86$ & $\begin{array}{l}20.29 \\
5.04\end{array}$ & $\begin{array}{l}\mathrm{t}(488)=.41, \mathrm{p}=0.679, \mathrm{~d} \\
=.039\end{array}$ \\
\hline Distress $^{\mathrm{C}}(\mathrm{M}, \mathrm{SD})$ & $\begin{array}{l}19.04 \\
(3.54)\end{array}$ & $18.98,3.45$ & $\begin{array}{l}19.17 \\
3.52\end{array}$ & $\begin{array}{l}t(488)=-.60, p=0.547, d \\
=.055\end{array}$ \\
\hline Suicidal ideation ${ }^{d}(M, S D)$ & $\begin{array}{l}12.66 \\
(5.99)\end{array}$ & $10.99,4.99$ & $\begin{array}{l}13.77 \\
6.31\end{array}$ & $\begin{array}{l}t(482)=-5.10, p<0.001 *, d \\
=.557\end{array}$ \\
\hline $\begin{array}{l}\text { Personal suicide stigma } \\
(M, S D)\end{array}$ & $\begin{array}{l}51.20 \\
(13.89)\end{array}$ & $\begin{array}{l}46.66 \\
14.46\end{array}$ & $\begin{array}{l}53.12 \\
13.22\end{array}$ & $\begin{array}{l}t(382)=-4.23, p<0.001 *, d \\
=.447\end{array}$ \\
\hline $\begin{array}{l}\text { Therapeutic alliance }{ }^{f}(M, \\
\text { SD) }\end{array}$ & $\begin{array}{l}79.76 \\
(17.84)\end{array}$ & $\begin{array}{l}74.20 \\
16.88\end{array}$ & $\begin{array}{l}83.23 \\
17.58\end{array}$ & $\begin{array}{l}t(462)=-5.46, p<0.001 *, d \\
=.329\end{array}$ \\
\hline \multicolumn{5}{|c|}{${ }^{\star} \mathrm{p}<.003$ denotes significance after Bonferroni adjustment } \\
\hline \multicolumn{5}{|c|}{ bMeasured with the Generalised Anxiety Disorder-7 Scale (GAD-7, Spitzer et al., 2006). } \\
\hline \multicolumn{5}{|c|}{ 'Measured with the Distress Questionnaire-5 (DQ5, Batterham et al., 2016). } \\
\hline \multicolumn{5}{|c|}{ d'Measured with the Suicidal Ideation Attributes Scale (SIDAS, van Spijker et al., 2014). } \\
\hline \multicolumn{5}{|c|}{ eMeasured with the Personal Suicide Stigma Questionnaire (PSSQ, Rimkeviciene et al., 2019). } \\
\hline \multicolumn{5}{|c|}{ fMeasured with the Revised Helping Alliance Questionnaire (HAq-II, Luborsky et al., 1996). } \\
\hline
\end{tabular}

Bivariate correlations were calculated between all variables under consideration (17 variables). After making Bonferroni corrections ( $p<.003)$, disclosure of suicidal ideation to a mental health professional (yes) had a large significant association with disclosure to anyone $(r=.518, p=.000)$, a medium association with prioritisation of suicidal ideation $(r=.326, p=.000)$, history of suicide attempt $(r=.305, p$ $=.000)$, and small associations with greater therapeutic alliance $(r=.246, p=.000)$, greater suicidal ideation severity $(r=.226, p=.000)$, greater personal stigma of suicide $(r=.211, p=.000)$, and sexual minority status $(r=.170, p=.000)$. 
Results from the binary logistic regression are presented in Table 2. 'Disclosure of suicidal ideation to anyone' was not included in the model as an independent variable due to low cell frequency (i.e., $n=5$ had disclosed to anyone and not a mental health professional). The addition of eight independent variables to a model that contained only the intercept significantly improved the fit, $\chi 2(8)=97.21, p<.001$. The model explained between 23.4\% (Cox and Snell R square) and 33.7\% (Nagelkerke R square) of the variance in disclosure of suicidal ideation to a mental health professional. When compared to no disclosure, significant unique contributions to disclosure of suicidal ideation were made by prioritisation of suicidal ideation, personal suicide stigma, therapeutic alliance, and lifetime history of attempt. Participants that were significantly more likely to disclose suicidal ideation to a mental health professional prioritised suicidal ideation as one of the top three most important mental health issues to discuss (4.07 times greater odds than those who did not prioritise suicidal ideation in their top three ranking) and had a history of suicide attempt (3.04 times greater odds than those with no attempt history). Participants had greater odds of disclosing suicidal ideation to a mental health professional for every one-point increase on the therapeutic alliance scale (by $4.1 \%$ ) and personal suicide stigma scale (by $3.7 \%)$.

Table 2

Binary Logistic Regression on Disclosure of Suicidal Ideation to a Mental Health Professional

\begin{tabular}{|c|c|c|c|c|}
\hline Predictors & B & Wald $\chi^{2}$ & OR & $95 \% \mathrm{Cl}$ \\
\hline Age & .149 & 3.530 & 1.161 & 0.99 to 1.36 \\
\hline Sexuality (heterosexual) & -.273 & .846 & .761 & 0.42 to 1.36 \\
\hline Suicidal ideation & .057 & 3.764 & 1.058 & 1.00 to 1.12 \\
\hline Prioritisation of SI (yes) & 1.404 & $24.681 * \star *$ & 4.072 & 2.34 to 7.09 \\
\hline Depression & -.049 & 2.034 & .952 & 0.89 to 1.02 \\
\hline Personal suicide stigma & .036 & $8.321^{\star \star}$ & 1.037 & 1.01 to 1.06 \\
\hline Therapeutic alliance & .040 & $24.723^{\star \star \star}$ & 1.041 & 1.02 to 1.06 \\
\hline Lifetime attempt (yes) & -1.111 & $13.838^{\star * *}$ & .329 & 0.18 to 0.59 \\
\hline \multicolumn{5}{|c|}{${ }^{\star} p<.05 ; * \star p<.01 ; * \star \star x<.001$} \\
\hline
\end{tabular}

\section{Reasons Behind Disclosure}

Participant responses to questions relating to disclosure of suicidal ideation to a MHP are presented in Table 3. 
Table 3

Reasons why participants chose to disclose, chose not to disclose, and what would motivate disclosure of suicidal ideation to a mental health professional.

\section{Reasons for disclosing suicidal thoughts to their mental health professional}

Response options

$n(\%)$

I'm worried that suicidal thoughts will not go away, and I want help to manage them

Suicidal thoughts are interfering with my life as much as/more than other mental health problems

I believe that a mental health professional can help with my suicidal thoughts

Someone I know told me I should tell my mental health professional

Other reason/s (free text response) $)^{a}$

I've talked about suicidal thoughts with a mental health professional in the past and found this helpful

Suicidal thoughts have become a relatively new problem and I want to deal with them

\section{Reasons for not disclosing suicidal thoughts to their mental health professional}

I'm concerned that my mental health professional wouldn't kept this information confidential

Suicidal thoughts are not interfering with my life as much as other mental health problems are

I think that suicidal thoughts will eventually go away, or are just a phase l'll grow out of, so there's no point talking about them

I've not talked about suicidal thoughts with a mental health professional in the past, but think that they will judge me or not respond well

Suicidal thoughts have become a normal part of my life

I don't think a mental health professional can do anything about my suicidal thoughts

My mental health professional has never asked about suicidal thoughts so I've never

I've talked about suicidal thoughts with a mental health professional in the past, was upset by their response, and don't want to share again 


\section{Reasons for disclosing suicidal thoughts to their mental health professional}

Factors that would increase motivation to disclose suicidal thoughts to a mental health professional

If I knew this information would be kept confidential and not be shared with others

If my mental health professional asked about suicidal thoughts

If I thought that suicidal thoughts could be treated/ helped

If I thought my mental health professional would respond without judgement

If the suicidal thoughts became more frequent or severe

If the suicidal thoughts started to interfere more with my work/ school/ relationships

Other reason/s (free text response) ${ }^{c}$

Note: each survey question allowed for endorsement of multiple response options.

aThe most common themes were 'Wanting to get help for their suicidal thoughts' $(n=25,36.2 \%)$ and 'Fear of current or future outcomes of acting on their suicidal thoughts' (n21,30.4\%). Additional themes and exemplar quotes are provided in Appendix B.

' $T$ The most common themes were 'Fear and consequences of disclosing' $(n=11,61.1 \%)$ and 'They were dismissive of their own thought' $(n=4,22.2 \%)$. Additional themes and exemplar quotes are provided in Appendix B.

'The most common themes were, 'Assurance of no hospitalisation' $(n=7,35.0 \%)$ and 'If they had a good relationship with their mental health professional' $(n=6,30.0 \%)$. Additional themes and exemplar quotes are provided in Appendix B.

\section{Discussion}

Although $100 \%$ of the current sample had reported experiencing suicidal ideation in the previous 12 months, we found that over one third (39\%) chose not to disclose, despite being engaged with a mental health professional. This finding suggests that each year many young people at risk for suicidal behaviour are missing out on the opportunity to receive clinical care for suicidal ideation. Young people who are engaged with a mental health professional are in the best possible position to receive effective evidence-based therapeutic intervention for their suicidal thoughts (D'Anci et al., 2019; Hofstra et al., 2020; Högberg \& Hällström, 2018), so understanding why they choose not to disclose is critical to developing strategies to address this issue. 
The findings in the present study showed that young people reported a number of barriers to disclosing suicidal ideation that were different to those preventing young people from seeking help for mental health concerns, as noted in earlier studies (e.g., Sheehan et al., 2019). A hesitancy to disclose suicidal ideation was greater among those who did not have a suicide attempt history, potentially leading to a lower prioritisation of suicidal ideation as a key concern. Just over half of the participants (59\%) ranked suicidal ideation as one of their top three most important mental health issues to discuss with a mental health professional, which was unexpected given that the entire sample had experienced suicidal ideation, compared to anxiety-related and depressive disorders, which were both ranked higher in priority. Consistent with this finding was that approximately half of the sample reported they would be motivated to disclose in future if their suicidal thoughts became more of a concern. The risk associated with suicide attempt and death is higher for suicidal ideation than it is for depression and anxiety, particularly as many suicide attempts by young people are a result of impulse rather than planning linked to intensity of ideation (Beckman et al., 2019; Conner et al., 2005; Jiang et al., 2010). Therefore, educating young people on the risk that suicidal ideation poses to their wellbeing could potentially encourage disclosure to mental health professionals.

Lower therapeutic alliance (less perceived closeness to and collaboration with the therapist, and lack of trusting the therapeutic process) was also associated with non-disclosure, as was the (false) belief that mental health professionals could not do anything to treat suicidal thoughts. Fewer positive expectations of treatment are typical amongst adolescents with depression and suicidal ideation, and this has been shown to predict future suicidal behaviour (Horwitz et al., 2017) and impede help-seeking (Michelmore \& Hindley, 2012). The challenges of establishing a strong therapeutic alliance with adolescents and engaging them in therapy is well known (Kim et al., 2012): youth are typically not self-referred and often enter into treatment unaware of their problems, and/or in conflict with their parents (DiGiuseppe et al., 1996; Shirk \& Karver, 2003). The success of establishing strong therapeutic relationships with young people is essential to improving their mental health outcomes (Karver et al., 2018) and may help to strengthen some of the motivations young people gave to disclose suicidal ideation in future (e.g., providing hope that suicidal thoughts can be treated/ helped, assurance that they would not receive negative judgement).

Gaining a young person's trust has emerged as a significant aspect of the alliance development in adolescents, particularly by explaining limits of confidentiality (Hawks, 2015; Manso et al., 2008). When participants were asked to indicate reasons for not disclosing suicidal ideation, the most reported reason was concern that their mental health practitioner would not keep this information confidential. The most common themes derived from free-text responses to reasons for not disclosing, and for motivating future disclosure, were 'fear and consequences of disclosing' (e.g., fear of being hospitalised) and 'assurance of no hospitalisation', respectively (see Appendix). Taken together, these findings indicate fears around uncertainty of repercussions for some young people if they choose to disclose. In general, adolescent concerns around confidentiality have been well documented (Michelmore \& Hindley, 2012; Radez et al., 2020). Research in medical settings also indicates that young people's motivations to disclose sensitive information are impeded when confidentiality is not assured (Ford et al., 2004; Lehrer et al., 2007). While 
psychologists practicing in Australia, America, and the UK are under no legal obligation to report this risk to others, unless there is an immediate and specified risk of harm to the young person that can be averted only by reporting this information (American Psychological Association, 2017; Australian Psychological Society, 2007; British Psychological Society, 2017), determining whether or not to breach confidentiality with a client in order to prevent harm can be a complicated and challenging process. Despite there being guidance about and support for confidentiality, ethical dilemmas and confusion amongst mental health professionals about when to breach confidentiality are widespread (Koocher, 2003; Walker, 2019). Better training concerning confidentiality and ethical decision-making processes have been proposed as a necessary strategy to maintain the delicate balance of managing confidentiality in a way that respects adolescents' developing autonomy, and protects the therapeutic relationship, while simultaneously protecting the young client from harm (Duncan et al., 2015; Sullivan et al., 2002). Training may also prompt clearer discussions with young people about the basic rules of confidentiality, what information is protected, and the limits to confidentiality. Doing so may alleviate unrealistic fears held by the young person and mitigate the likelihood of them choosing to conceal symptoms or forgo care altogether (as has been demonstrated in medical settings; Farrant \& Watson, 2004; Jones et al., 2005; Lehrer et al., 2007; Reddy et al., 2002).

Concerningly, some young people reported not disclosing suicidal thoughts to their mental health practitioner because they were not directly asked. It may help to address non-disclosure and associated suicide risk of young people seeking treatment if mental health professionals incorporate into their continual professional development plan, activities and practices to enhance their therapeutic relationships with young clients (e.g., see Ackerman \& Hilsenroth, 2003; Becker et al., 2018) and the quality and scope of their risk assessments. For example, conducting periodic assessments of suicide risk over the course of treatment, and not just during the initial session, is necessary because suicidal ideation fluctuates dramatically (Harmer et al., 2020; Kleiman et al., 2017). Moreover, conducting suicide risk assessments more routinely may increase provider confidence in handling suicide risk while also increasing the young person's exposure to - and potential comfort in answering these questions (Cukrowicz et al., 2014).

Interestingly, reports of greater personalised suicide stigma were associated with disclosing suicidal ideation to a mental health professional. This finding is counter intuitive, as suicide stigma has been found to be a reported barrier to young people seeking help for mental health problems (Rickwood et al., 2005; Sheehan et al., 2019). As most of the items on the Personalised Suicide Stigma Scale focus on perceived rejection from friends and family following disclosure - rather than health professionals - this scale appears to be a measure of stigma resulting from negative interactions with informal supports, specifically. Therefore, an explanation for our finding might be that a greater degree of personalised suicide stigma, resulting from negative interactions with informal supports, leads to a desire to disclose suicidal ideation to formal support as an alternative when seeking help for suicide. Future research should examine whether different types of stigma (of which there are at least eight, see Sheehan et al., 2017) influence pathways for young people seeking help for and disclosing suicidal thoughts and behaviours.

Page $14 / 22$ 


\section{Limitations}

There are several limitations that should be acknowledged. First, there were a disproportionate number of females (84\%) and participants identifying as having a sexual minority status $(69 \%)$ compared to what is represented in the general Australian population, at 50.7\% (Australian Bureau of Statistics, 2016) and 4\% (Australian Bureau of Statistics, 2021), respectively. However, considering our inclusion criteria to participate, this profile was not surprising as young females report experiencing higher rates of suicidal ideation (Fergusson et al., 2000) and help-seeking for help for mental health problems than males (Bergeron et al., 2005). This trend is also seen amongst sexual minority youth compared to their heterosexual peers (Williams \& Chapman, 2011). However, given the exploratory nature of this study, imbalances in the sample are less of threat to validity than confirmatory studies. Second, as most of our sample were aged 17 years, the findings may not fully reflect the experience of young people outside of this age range. Third, the study was based on cross-sectional data and causal relationships cannot be determined. Fourth, the pre-determined answers on our questionnaire may have led participants, and though we did include free text responses, qualitative interviews would have provided a richer understanding of the topics explored. Fifth, the sample size was not large enough to conduct subanalyses (e.g., to examine whether confidentiality was more of a concern for young people under 18 years). Last, the accuracy of self-report measures is limited by honesty and introspective ability of respondents, and a multiple method approach to data collection would be ideal.

\section{Conclusions}

Young people engaged with a mental health professional are best placed to receive treatment for their suicidal thoughts, yet this study shows that more than one-third of young people choose not to disclose suicidal thoughts to their mental health practitioner. These participants were more likely to report no history of suicide attempts, a low priority of their suicidal thoughts, lower therapeutic alliance, and lower personal suicide stigma. The findings suggest several strategies for improving disclosure to mental health professionals, including ways to psycho-educate young people on why disclosing ideation is important, and allaying fears around uncertainty of repercussions if they choose to disclose. For clinicians, training in how to conduct ongoing risk assessments over the course of treatment - including how to directly ask about ideation and respond to it - will be important to implement in tandem with any strategies directly focused on young people, to create a systems response to creating safety to disclose.

\section{Declarations}

Ethics approval and consent to participate: Ethics approval for this study was obtained from the University of New South Wales Human Research Ethics Committee (HC200465). All procedures performed in the study involving human participants were in accordance with the ethical standards of the institutional and/or national research committee and with the 1964 Helsinki declaration and its later amendments or comparable ethical standards. As such, informed consent to participate was obtained from all participants prior to data collection. 
Consent for publication: Not applicable. No images or identifiable data are reported within the manuscript.

Availability of data and materials: The datasets generated and/or analysed during the current study are not publicly available due to the sensitive nature of the data collected from minors but are available from the corresponding author on reasonable request.

Competing interests: No potential competing interests were reported by the authors.

Funding: NHMRC Early Career Fellowship (GNT1138710)

Author's contributions: LM and MT conceived the study. LM, MT, and DR developed the survey and $A B$ built the survey. LM and DR conducted the analyses. JW contributed to drafting sections of the manuscript. All authors contributed to preparation of the final manuscript. The corresponding author attests that all listed authors meet authorship criteria and that no others meeting the criteria have been omitted.

Acknowledgements: We would like to acknowledge the participants involved in this study who provided insights into their lived experience of suicidal ideation. This study was inspired by the participants involved in an earlier clinical trial who requested anonymous clinical support (all of which, were engaged with a mental health professional at the time).

\section{References}

1. Ackerman, S. J., \& Hilsenroth, M. J. (2003). A review of therapist characteristics and techniques positively impacting the therapeutic alliance. Clinical Psychology Review, 23(1), 1-33. https://doi.org/https://doi.org/10.1016/S0272-7358(02)00146-0

2. American Psychological Association. (2017). Ethical principles of psychologists and code of conduct (amended effective June 1, 2010, and January 1, 2017). Retrieved from: http://www.apa.org/ethics/code/index.html

3. Australian Bureau of Statistics. (2016). Census of population and housing. Retrieved 20th July from https://quickstats.censusdata.abs.gov.au/census_services/getproduct/census/2016/quickstat/1

4. Australian Bureau of Statistics. (2021). General social survey: Summary results, Australia. Retrieved 20th July from https://www.abs.gov.au/statistics/people/people-and-communities/general-socialsurvey-summary-results-australia/latest-release

5. Australian Psychological Society. (2007). Code of ethics. Retrieved 29 July 2021 from https://www.psychology.org.au/getmedia/d873e0db-7490-46de-bb57-c31bb1553025/18APS-Codeof-Ethics.pdf

6. Barber, J., Luborsky, L., Crits-Christoph, P., Thase, M., Weiss, R., Frank, A., Onken, L., \& Gallop, R. (1999). Therapeutic alliance as a predictor of outcome in treatment of cocaine dependence. Psychotherapy Research, 9(1), 54-73. https://doi.org/10.1080/10503309912331332591 
7. Batterham, P. J., Sunderland, M., Carragher, N., Calear, A. L., Mackinnon, A. J., \& Slade, T. (2016). The Distress Questionnaire-5: Population screener for psychological distress was more accurate than the K6/K10. Journal of Clinical Epidemiology, 71, 35-42. https://doi.org/10.1016/j.jclinepi.2015.10.005

8. Becker, K. D., Boustani, M., Gellatly, R., \& Chorpita, B. F. (2018). Forty years of engagement research in children's mental health services: Multidimensional measurement and practice elements. Journal of Clinical Child \& Adolescent Psychology, 47(1), 1-23. https://doi.org/https://doi.org/10.1080/15374416.2017.1326121

9. Beckman, K., Lindh, A. U., Waern, M., Stromsten, L., Renberg, E. S., Runeson, B., \& Dahlin, M. (2019). Impulsive suicide attempts among young people-A prospective multicentre cohort study in Sweden. Journal of Affective Disorders, 243, 421-426. https://doi.org/10.1016/j.jad.2018.09.070

10. Bergeron, E., Poirier, L. R., Fournier, L., Roberge, P., \& Barrette, G. (2005). Determinants of service use among young Canadians with mental disorders. The Canadian Journal of Psychiatry, 50(10), 629636. https://doi.org/10.1177/070674370505001009

11. British Psychological Society. (2017). BPS practice guidelines. https://www.bps.org.uk/news-andpolicy/practice-guidelines

12. Bruffaerts, R., Demyttenaere, K., Hwang, I., Chiu, W. T., Sampson, N., Kessler, R. C., Alonso, J., Borges, G., de Girolamo, G., de Graaf, R., Florescu, S., Gureje, O., Hu, C., Karam, E. G., Kawakami, N., Kostyuchenko, S., Kovess-Masfety, V., Lee, S., Levinson, D., Matschinger, H., Posada-Villa, J., Sagar, R., Scott, K. M., Stein, D. J., Tomov, T., Viana, M. C., \& Nock, M. K. (2011). Treatment of suicidal people around the world. The British Journal of Psychiatry, 199(1), 64-70.

https://doi.org/10.1192/bjp.bp.110.084129

13. Cohen, J. (2013). Statistical power analysis for the behavioral sciences. Academic Press.

14. Conner, K. R., Phillips, M. R., Meldrum, S., Knox, K. L., Zhang, Y., \& Yang, G. (2005). Low-planned suicides in China. Psychological Medicine, 35(8), 1197-1204.

https://doi.org/10.1017/s003329170500454x

15. Cukrowicz, K. C., Duberstein, P. R., Vannoy, S. D., Lin, E. H., \& Unützer, J. (2014). What factors determine disclosure of suicide ideation in adults 60 and older to a treatment provider? Suicide and Life-Threatening Behavior, 44(3), 331-337. https://doi.org/10.1111/sltb.12075

16. D'Anci, K. E., Uhl, S., Giradi, G., \& Martin, C. (2019). Treatments for the prevention and management of Suicide: A systematic review. Annals of Internal Medicine, 171(5), 334-342. https://doi.org/10.7326/m19-0869

17. DeCou, C. R., Comtois, K. A., \& Landes, S. J. (2019). Dialectical behavior therapy is effective for the treatment of suicidal behavior: A meta-analysis. Behavior Therapy, 50(1), 60-72. https://doi.org/https://doi.org/10.1016/j.beth.2018.03.009

18. DiGiuseppe, R., Linscott, J., \& Jilton, R. (1996). Developing the therapeutic alliance in childadolescent psychotherapy. Applied and Preventive Psychology, 5(2), 85-100. https://doi.org/https://doi.org/10.1016/S0962-1849(96)80002-3 
19. Donath, C., Bergmann, M. C., Kliem, S., Hillemacher, T., \& Baier, D. (2019). Epidemiology of suicidal ideation, suicide attempts, and direct self-injurious behavior in adolescents with a migration background: A representative study. BMC Pediatrics, 19(1), 1-15. https://doi.org/https://doi.org/10.1186/s12887-019-1404-z

20. Duncan, R. E., Hall, A. C., \& Knowles, A. (2015). Ethical dilemmas of confidentiality with adolescent clients: Case studies from psychologists. Ethics \& Behavior, 25(3), 197-221. https://doi.org/https://doi.org/10.1080/10508422.2014.923314

21. Farrant, B., \& Watson, P. D. (2004). Health care delivery: Perspectives of young people with chronic illness and their parents. Journal of Paediatrics and Child Health, 40(4), 175-179. https://doi.org/https://doi.org/10.1111/j.1440-1754.2004.00333.x

22. Fergusson, D. M., Woodward, L. J., \& Horwood, L. J. (2000). Risk factors and life processes associated with the onset of suicidal behaviour during adolescence and early adulthood. Psychological Medicine, 30(1), 23-39. https://doi.org/10.1017/s003329179900135x

23. Ford, C., English, A., \& Sigman, G. (2004). Confidential health care for adolescents: Position paper of the Society for Adolescent Medicine. Journal of Adolescent Health, 35(2), 160-167. https://doi.org/https://doi.org/10.1016/j.jadohealth.2004.03.002

24. Frey, L., Hans, J., \& Cerel, J. (2015). Perceptions of suicide stigma: How do social networks and rreatment providers compare? Crisis The Journal of Crisis Intervention and Suicide Prevention, 37. https://doi.org/10.1027/0227-5910/a000358

25. Funder, D. C., \& Ozer, D. J. (2019). Evaluating effect size in psychological research: Sense and nonsense. Advances in Methods and Practices in Psychological Science, 2(2), 156-168. https://doi.org/https://doi.org/10.1177/2515245919847202

26. Griffith, R. (2016). What is Gillick competence? Human Vaccines and Immunotherapeutics, 12(1), 244-247. https://doi.org/10.1080/21645515.2015.1091548

27. Griffiths, K. M., Crisp, D. A., Barney, L., \& Reid, R. (2011). Seeking help for depression from family and friends: A qualitative analysis of perceived advantages and disadvantages. BMC Psychiatry, 11(1), 196. https://doi.org/10.1186/1471-244X-11-196

28. Harmer, B., Lee, S., Duong, T., \& Saadabadi, A. (2020). Suicidal Ideation. StatPearls Publishing.

29. Hawks, J. M. (2015). Exploring the therapeutic alliance with adolescents and their caregivers: $A$ qualitative approach. University of Kentucky.

30. Hofstra, E., van Nieuwenhuizen, C., Bakker, M., Özgül, D., Elfeddali, I., de Jong, S. J., \& van der FeltzCornelis, C. M. (2020). Effectiveness of suicide prevention interventions: A systematic review and meta-analysis. General Hospital Psychiatry, 63, 127-140. https://doi.org/https://doi.org/10.1016/j.genhosppsych.2019.04.011

31. Högberg, G., \& Hällström, T. (2018). Mood regulation focused CBT based on memory reconsolidation, reduced suicidal ideation and depression in youth in a randomised controlled study. International Journal of Environmental Research and Public Health, 15(5), 921. https://doi.org/10.3390/ijerph15050921 
32. Hom, M. A., Stanley, I. H., \& Joiner Jr, T. E. (2015). Evaluating factors and interventions that influence help-seeking and mental health service utilization among suicidal individuals: A review of the literature. Clinical Psychology Review, 40, 28-39. https://doi.org/10.1016/j.cpr.2015.05.006

33. Hooven, C. (2013). Parents-CARE: A suicide prevention program for parents of at-risk youth. Journal of Child Adolescent Psychiatric Nursing, 26(1), 85-95. https://doi.org/10.1111/jcap.12025

34. Horwitz, A. G., Berona, J., Czyz, E. K., Yeguez, C. E., \& King, C. A. (2017). Positive and negative expectations of hopelessness as longitudinal predictors of depression, suicidal ideation, and suicidal behavior in high-risk adolescents. Suicide and Life-Threatening Behavior, 47(2), 168-176. https://doi.org/10.1111/sltb.12273

35. Jiang, Y., Perry, D. K., \& Hesser, J. E. (2010). Suicide patterns and association with predictors among Rhode Island public high school students: A latent class analysis. American Journal of Public Health, 100(9), 1701-1707. https://doi.org/10.2105/ajph.2009.183483

36. Jones, R. K., Purcell, A., Singh, S., \& Finer, L. B. (2005). Adolescents' reports of parental knowledge of adolescents' use of sexual health services and their reactions to mandated parental notification for prescription contraception. JAMA, 293(3), 340-348. https://doi.org/doi:10.1001/jama.293.3.340

37. Karver, M. S., De Nadai, A. S., Monahan, M., \& Shirk, S. R. (2018). Meta-analysis of the prospective relation between alliance and outcome in child and adolescent psychotherapy. Psychotherapy, 55(4), 341. https://doi.org/https://doi.org/10.1037/pst0000176

38. Kim, H., Munson, M. R., \& McKay, M. M. (2012). Engagement in mental health treatment among adolescents and young adults: A systematic review. Child and Adolescent Social Work Journal, 29(3), 241-266. https://doi.org/https://doi.org/10.1007/s10560-012-0256-2

39. Kleiman, E. M., Turner, B. J., Fedor, S., Beale, E. E., Huffman, J. C., \& Nock, M. K. (2017). Examination of real-time fluctuations in suicidal ideation and its risk factors: Results from two ecological momentary assessment studies. Journal of Abnormal Psychology, 126(6), 726-738. https://doi.org/10.1037/abn0000273

40. Koocher, G. P. (2003). Ethical issues in psychotherapy with adolescents. Journal of Clinical Psychology, 59(11), 1247-1256. https://doi.org/10.1002/jclp.10215

41. Kroenke, K., Spitzer, R. L., \& Williams, J. B. (2001). The PHQ-9: Validity of a brief depression severity measure. Journal of General Internal Medicine, 16(9), 606-613. https://doi.org/10.1046/j.15251497.2001.016009606.x

42. Kroenke, K., Wu, J., Yu, Z., Bair, M. J., Kean, J., Stump, T., \& Monahan, P. O. (2016). Patient Health Questionnaire Anxiety and Depression Scale: Initial validation in three clinical trials. Psychosomatic Medicine, 78(6), 716-727. https://doi.org/10.1097/psy.0000000000000322

43. Leavey, K., \& Hawkins, R. (2017). Is cognitive behavioural therapy effective in reducing suicidal ideation and behaviour when delivered face-to-face or via e-health? A systematic review and metaanalysis. Cognitive Behaviour Therapy, 46(5), 353-374.

https://doi.org/https://doi.org/10.1080/16506073.2017.1332095 
44. Lehrer, J. A., Pantell, R., Tebb, K., \& Shafer, M.-A. (2007). Forgone health care among US adolescents: Associations between risk characteristics and confidentiality concern. Journal of Adolescent Health, 4O(3), 218-226. https://doi.org/10.1016/j.jadohealth.2006.09.015

45. Luborsky, L., Barber, J. P., Siqueland, L., Johnson, S., Najavits, L. M., Frank, A., \& Daley, D. (1996). The Revised Helping Alliance Questionnaire (HAq-II): Psychometric properties. Journal of Psychotherapy Practice and Research, 5(3), 260-271.

46. Manso, A., Rauktis, M. E., \& Boyd, A. S. (2008). Youth expectations about therapeutic alliance in a residential setting. Residential Treatment for Children \& Youth, 25(1), 55-72. https://doi.org/10.1080/08865710802209826

47. Maple, M., \& Sanford, R. (2020). Suicide exposure and impact within a non-representative Australian community sample. Death Studies, 44(6), 329-337.

https://doi.org/10.1080/07481187.2018.1554609

48. Meerwijk, E. L., Parekh, A., Oquendo, M. A., Allen, I. E., Franck, L. S., \& Lee, K. A. (2016). Direct versus indirect psychosocial and behavioural interventions to prevent suicide and suicide attempts: $A$ systematic review and meta-analysis. Lancet Psychiatry, 3(6), 544-554.

https://doi.org/10.1016/S2215-0366(16)00064-X

49. Michelmore, L., \& Hindley, P. (2012). Help-seeking for suicidal thoughts and self-harm in young people: A systematic review. Suicide and Life-Threatening Behavior, 42(5), 507-524. https://doi.org/10.1111/j.1943-278X.2012.00108.x

50. Miranda, R., Ortin, A., Scott, M., \& Shaffer, D. (2014). Characteristics of suicidal ideation that predict the transition to future suicide attempts in adolescents. Journal of Child Psychology and Psychiatry, 55(11), 1288-1296. https://doi.org/https://doi.org/10.1111/jcpp.12245

51. Nock, M. K., Borges, G., Bromet, E. J., Cha, C. B., Kessler, R. C., \& Lee, S. (2008). Suicide and suicidal behavior. Epidemiologic Reviews, 30(1), 133-154. https://doi.org/10.1093/epirev/mxn002

52. Nock, M. K., Green, J. G., Hwang, I., McLaughlin, K. A., Sampson, N. A., Zaslavsky, A. M., \& Kessler, R. C. (2013). Prevalence, correlates, and treatment of lifetime suicidal behavior among adolescents: Results from the National Comorbidity Survey Replication Adolescent Supplement. JAMA Psychiatry, 70(3), 300-310. https://doi.org/10.1001/2013.jamapsychiatry.55

53. Radez, J., Reardon, T., Creswell, C., Lawrence, P. J., Evdoka-Burton, G., \& Waite, P. (2020). Why do children and adolescents (not) seek and access professional help for their mental health problems? A systematic review of quantitative and qualitative studies. European Child \& Adolescent Psychiatry, 30(2), 183-211. https://doi.org/10.1007/s00787-019-01469-4

54. Ranganathan, P., Pramesh, C. S., \& Aggarwal, R. (2017). Common pitfalls in statistical analysis: Logistic regression. Perspectives in Clinical Research, 8(3), 148-151. https://doi.org/10.4103/picr.PICR_87_17

55. Reddy, D. M., Fleming, R., \& Swain, C. (2002). Effect of mandatory parental notification on adolescent girls' use of sexual health care services. JAMA, 288(6), 710-714. https://doi.org/10.1001/jama.288.6.710DOI 
56. Rickwood, D., Deane, F. P., Wilson, C. J., \& Ciarrochi, J. (2005). Young people's help-seeking for mental health problems. Australian e-Journal for the Advancement of Mental Health, 4(3), 218-251. https://doi.org/10.5172/jamh.4.3.218

57. Rimkeviciene, J., Mok, K., Shand, F., Hawgood, J., \& O'Gorman, J. (2021). Validity of the Personal Suicide Stigma Questionnaire in a community sample. European Journal of Psychological Assessment, Advance online publication. https://doi.org/https://doi.org/10.1027/1015$5759 / \mathrm{a} 000635$

58. Rimkeviciene, J., O'Gorman, J., Hawgood, J., \& De Leo, D. (2019). Development and validity of the Personal Suicide Stigma Questionnaire (PSSQ). Crisis, 40(5), 317-325. https://doi.org/10.1027/0227-5910/a000567

59. Rowe, S. L., French, R. S., Henderson, C., Ougrin, D., Slade, M., \& Moran, P. (2014). Help-seeking behaviour and adolescent self-harm: A systematic review. Australian \& New Zealand Journal of Psychiatry, 48(12), 1083-1095. https://doi.org/10.1177/0004867414555718

60. Sheehan, L., Nieweglowski, K., \& Corrigan, P. W. (2017). Structures and Types of Stigma. In W. Gaebel, W. Rössler, \& N. Sartorius (Eds.), The Stigma of Mental Illness - End of the Story? (pp. 43-66). Springer International Publishing. https://doi.org/10.1007/978-3-319-27839-1_3

61. Sheehan, L., Oexle, N., Armas, S. A., Wan, H. T., Bushman, M., Glover, L., \& Lewy, S. A. (2019). Benefits and risks of suicide disclosure. Social Science \& Medicine, 223, 16-23.

https://doi.org/https://doi.org/10.1016/j.socscimed.2019.01.023

62. Shirk, S. R., \& Karver, M. (2003). Prediction of treatment outcome from relationship variables in child and adolescent therapy: A meta-analytic review. Journal of Consulting and Clinical Psychology, 71(3), 452-464. https://doi.org/10.1037/0022-006x.71.3.452

63. Spitzer, R. L., Kroenke, K., Williams, J. B., \& Löwe, B. (2006). A brief measure for assessing generalized anxiety disorder: the GAD-7. Archives of Internal Medicine, 166(10), 1092-1097. https://doi.org/10.1001/archinte.166.10.1092

64. Sullivan, J. R., Ramirez, E., Rae, W. A., Razo, N. R., \& George, C. A. (2002). Factors contributing to breaking confidentiality with adolescent clients: A survey of pediatric psychologists. Professional Psychology: Research and Practice, 33(4), 396-401. https://doi.org/https://doi.org/10.1037/07357028.33.4.396

65. Torok, M., Han, J., Baker, S., Werner-Seidler, A., Wong, I., Larsen, M. E., \& Christensen, H. (2020). Suicide prevention using self-guided digital interventions: a systematic review and meta-analysis of randomised controlled trials. Lancet Digital Health, 2(1), e25-e36. https://doi.org/https://doi.org/10.1016/S2589-7500(19)30199-2

66. van Spijker, B. A., Batterham, P. J., Calear, A. L., Farrer, L., Christensen, H., Reynolds, J., \& Kerkhof, A. J. (2014). The suicidal ideation attributes scale (SIDAS): Community-based validation study of a new scale for the measurement of suicidal ideation. Suicide and Life-Threatening Behaviour, 44(4), 408419. https://doi.org/10.1111/sltb.12084 
67. Voss, C., Ollmann, T. M., Miché, M., Venz, J., Hoyer, J., Pieper, L., Höfler, M., \& Beesdo-Baum, K. (2019). Prevalence, onset, and course of suicidal behavior among adolescents and young adults in Germany. JAMA Network Open, 2(10), e1914386-e1914386. https://doi.org/10.1001/jamanetworkopen.2019.14386

68. Walker, S. (2019). Confidentiality and practice in child and adolescent mental health. Ethics and Social Welfare, 13(3), 302-308. https://doi.org/https://doi.org/10.1080/17496535.2019.1649444

69. Walsh, E., Hooven, C., \& Kronick, B. (2013). School-wide staff and faculty training in suicide risk awareness: Successes and challenges. Ethics and Social Welfare, 26(1), 53-61. https://doi.org/ https://doi.org/10.1080/17496535.2019.1649444

70. Watanabe, N., Nishida, A., Shimodera, S., Inoue, K., Oshima, N., Sasaki, T., Inoue, S., Akechi, T., Furukawa, T. A., \& Okazaki, Y. (2012). Help-seeking behavior among Japanese school students who self-harm: Results from a self-report survey of 18,104 adolescents. Neuropsychiatric Disease and Treatment, 8, 561-569. https://doi.org/10.2147/ndt.S37543

71. Williams, K. A., \& Chapman, M. V. (2011). Comparing health and mental health needs, service use, and barriers to services among sexual minority youths and their peers. Health \& Social Work, 36(3), 197-206. https://doi.org/10.1093/hsw/36.3.197

72. World Health Organization. (2013). Mental health action plan 2013-2020. Retrieved from: https://apps.who.int/iris/bitstream/handle/10665/89966/9789241506021_eng.pdf

73. World Health Organization. (2019). Suicide worldwide in 2019: Global health estimates. Retrieved from: file:///C:/Users/z5075949/Downloads/9789240026643-eng\%20(1).pdf

\section{Supplementary Files}

This is a list of supplementary files associated with this preprint. Click to download.

- Appendix230921.docx 